\title{
CHANGES IN IMPLICIT LEADERSHIP THEORY CONSTELLATIONS THROUGHOUT A DEVELOPMENTAL EXPERIENCE
}

\begin{abstract}
Challenging, novel, and educational experiences are critical contributors to effective leader and follower development, in part, because such developmental experiences enable people to reconceptualize their perceptions about the traits and characteristics of effective leaders, or their implicit leadership theory (ILT). To understand how ILTs develop throughout developmental experiences, we examine the ILTs of 276 undergraduate students at the beginning and end of their first year of college. Using an open-ended ILT response format, a unique ILT trait of integrity emerged along with the dominant ILT traits of sensitivity, charisma, and dedication identified in previous literature. Overcoming limitations of the factor-based ILT approach, we investigate the development of ILT constellations, allowing a holistic picture of ILTs and how they throughout a developmental experience. Based on cluster analyses, four constellations of ILT themes emerged. Participants shifted to different ILT constellations after a year in college, moving from a non-descript, varied constellation toward constellations with clearly defined, dominant themes. Exploratory analysis revealed that completion of leadership coursework partially explains the shift towards more descript ILT constellations. Results have implications for new methods of future research using the ILTs constellation perspective and the practice of undergraduate leadership education in facilitating leader development among college students.
\end{abstract}

\section{Introduction}

In the United States and around the world today, there are many contrasting views about the traits and characteristics that make a leader effective, which has implications for individuals' likelihood of perceiving others and themselves as leaders. Some followers, for example, view the prototypical dimension of "strength" as a defining characteristic of a leader (Offerman et al., 1994). They believe a leader is someone who states their point of view assertively, is decisive, and does not back down. When they observe an individual displaying the trait of strength, they are likely to view the person as an effective leader, like them, and grant them leadership by following them (Johnson et al., 2008). Similarly, when attempting to enact leadership, those individuals holding the view that strength defines leadership would be more likely to demonstrate strength in their behaviors and interactions with others. If they fail to do so, they would evaluate themselves as lacking what it takes to be a leader and be less motivated to fill leadership roles (Guillén et al., 2015).

One's assumptions regarding the traits and characteristics that define a leader are referred to as implicit leadership theories (ILTs; Lord et al., 1984). 
These assumptions form cognitive structures known as mental models or "schemas" that organize people or things into categories to facilitate efficient mental processing (Fiske \& Taylor, 1991). Just as we hold a schema for the traits and characteristics of a dog (e.g., furry, has a tail, barks at strangers) based on our experiences and exposure to one or more dogs throughout our lifetime, we similarly form schemas of the traits and characteristics of a leader (e.g., strong, attractive, charismatic) based on our experiences with leadership.

ILTs have a powerful influence on several leadership processes and outcomes (Schyns \& Meindl, 2005). ILTs influence follower perceptions of the leader and, thus, follower behavior as a result (Jelinek et al., 1983). When we observe a leader, we automatically activate our ILTs to quickly make unconscious evaluations of them against our existing schema (Hall \& Lord, 1995; Kenney et al., 1996). Leaders who fit a followers' ILT are more likely to be liked (Nye \& Forsyth, 1991), perceived to have more technical competence (Sy et al., 2010), and preferred as leaders (Hall et al., 1998). Followers show more respect towards leaders who fit their ideal leader image (Van Quaquebeke \& Van Knippenberg, 2012), are more committed to their job, and report higher job satisfaction (Epitropaki \& Martin, 2005). From the stance of the leader, ILTs influence one's leader identity, or perceptions of oneself as a leader. When evaluating oneself as a leader, we compare our ILTs with perceptions of our personal characteristics to answer the question, "Am I leader-like?" (Engle \& Lord, 1997). Thus, ILTs impact both inter- and intrapersonal aspects of organizational behavior.

Given the wide influence ILTs have on organizational behavior, scholars have conducted a great deal of research on the topic (see reviews by Epitropaki et al., 2013; Junker \& van Dick, 2014; Lord et al., 2020). Early studies of ILTs frequently employed narrative methods (Epitropaki et al., 2013), though scholars soon shifted to using quantitative methods with the development of Likert-style measures of ILTs which ask participants to rate the prototypicality of a list of leader traits. For example, Offermann et al. (1994) identified eight ILT traits (e.g., tyranny, charisma, attractiveness, strength, and masculinity), some considered prototypical (e.g., charisma) and some as anti-prototypical (e.g., tyranny; Epitropaki \& Martin, 2004). We refer to this as a factorbased method because singular, pre-determined ILT traits are rated and considered independently.

However, this factor-based method may be overly simplistic for several reasons. First, quantitative measures constrain reports of ILTs to a fixed list of attributes pre-determined by the researcher. This approach limits the extent to which we can assess emerging ILTs based on generational, cultural, or other sample-related uniqueness; whereas, we know that new ILTs may emerge as dominant over time as Offermann and Coats (2018) recently identified additional ILT traits (e.g., creativity). In fact, a criticism of ILTs identified by Dugan (2017) is that ILTs reflect ideological and hegemonic assumptions about who a leader is and how they should behave. Dominant leader prototypes may reproduce systemic biases and or disadvantage individuals who do not "fit" traditional leader prototypes. Second, it cannot capture the complexity of cognitive schemas, including the extent to which a person simultaneously views two (or more) leadership traits as effective. Past research using such quantitative measures have found strong positive correlations between ILT factors (e.g., Carnes et al., 2015), suggesting that individuals frequently hold multiple ILTs. Yet, this complexity is not captured in the typically employed factor-based quantitative measurement of ILTs because of the emphasis on singular ILT dimensions. Finally, the typical factorbased approach to measuring ILTs does not allow us to assess relative changes in multiple ILT dimensions at once, thus we cannot examine the malleability of the ILT dimension list over time Junker \& van Dick, 2014).

Instead, we propose a more comprehensive measurement approach in which ILTs are assessed qualitatively as constellations of emergent traits, instead of siloed predetermined traits. We define ILT constellations as the cognitive schema one holds regarding the profile of traits and characteristics of effective leaders. So just as we view a dog as more than a singular trait (e.g., furry), our ILT constellations 
of leaders are multi-faceted and complex (e.g., strong, intelligent, and charismatic). Like the initial ILT studies, the qualitative assessment of ILT constellations proposed here allows for the emergence of new dimensions and themes not reflected in predetermined scales. We expect that not only will ILTS vary across time with different leader traits being view as more or less dominant (e.g., Offermann \& Coats, 2018), but that different genders, racial groups, and age groups will hold different ILTs, which may not be captured in the pre-determined list researchers typically employ. Finally, using a constellation approach to defining and measuring ILTs, we can simultaneously consider the content, complexity, and structure of ILTs and how these change over time.

In addition to introducing ILTs as constellations of traits, we evaluate possible changes in ILT constellations throughout a developmental experience (i.e., the first year of college). Despite recent evidence suggesting that the ILTs society collectively endorses have remained fairly stable for the past 20 years (Offermann \& Coats, 2018), relatively little is known about how any given individual's image of leaders might change over time. For instance, why or how someone might begin to favor leadership sensitivity over strength (or vice versa) remains unclear. For example, in their prospective, longitudinal study, Walker and colleagues (2020) found that high family conflict during formative adolescent years is positively predictive of adults endorsing a tyrannical ILT. Junker and van Dick (2014) illuminate a need for further longitudinal assessments of the stability of ILTs, pointing to the gap in our understanding of how ILTs are formed and molded in any one person over time. Significant developmental experiences likely influence the traits and attributes we ascribe to effective leaders because such events can reshape values, goals, and ways of making sense of the world. Thus, we chose first-year college students because of the assumed importance of the college experience in shifting one's assumptions and beliefs.

Although we do not take a critical lens of deconstruction of ILTs, we do seek to contribute to the ILT and leader development literatures in several ways. First, our study advances a profile approach to ILT measurement that captures a more nuanced, multi-faceted picture of a person's ideal leader image. Second, by using qualitative open coding, we reconsider the emergent theme of leader integrity as a stand-alone ILT dimension. Third, we examine how ILT profiles might change over the course of a student's first year in college and, thus, point to new avenues for leader development theory and practice.

In what follows, we propose four research questions aimed at understanding the content, constellations, and malleability of ILTs. We take a multi-method approach, first by qualitatively examining and categorizing ILT dimensions. Next, we utilize agglomerative hierarchical clustering analyses to explore the content of constellations of ILTs over the first year of college. Finally, we discuss how ILT dimensions and constellations may change throughout significant developmental experiences.

\section{Implicit Leadership Theories}

ILTs can be understood through the lens of leadership categorization theory, which asserts that people group beliefs about leading and leadership into a hierarchical mental model in which the attributes they believe to be prototypical of leaders are distinct attributes from non-leaders (Lord et al., 1982; Rosch, 1978). In this section, we discuss theory and research on ILT content, constellations, and malleability culminating in our research questions.

ILT Content. Initially, researchers qualitatively examined the content of ILTs and based on those findings subsequently developed a factor-based quantitative survey. The first list of prototypical leader traits was developed in the 1990s by Offermann and colleagues (1994). First, one group of students generated a list of 160 leader traits. Next, a different set of students rated the extent to which each trait was characteristic of a leader. Through factor analysis, eight ILT dimensions emerged as dominant: sensitivity, dedication, tyranny, charisma, attractiveness, masculinity, intelligence, and strength. As 
demonstrated by these emergent categories, schemas for leaders include both positive (e.g., intelligent) and negative (e.g., tyrannical) characteristics (Offermann et al., 1994).

In the early 2000s, Epitropaki and Martin (2004) crossvalidated and simplified this list into six dimensions of ILT traits, further grouped as "prototypical" or "anti-prototypical." Prototypical leader attributes are those frequently rated as highly representative of a leader (i.e., sensitivity, dedication, dynamism, and intelligence), whereas anti-prototypical attributes were those less frequently rated as representative of a leader (i.e., tyranny and masculinity). Epitropaki and Martin determined these two higher-order categories by extending prior use of cognitive categorization theory in understanding ILTs (Lord et al., 1984; Rosch, 1978).

In 2018, Offermann and Coats published a replication study of Offermann and colleagues' 1994 study to assess the stability of ILTs over 20 years, finding 76\% overlap in words generated. However, "creativity" emerged as a new ILT factor not identified by the 1994 sample. Furthermore, there were several new traits generated by the more recent sample (e.g., culturally competent, emotionally intelligent) and several traits that loaded onto different ILT factors (e.g., the trait "bold" loaded onto the "charisma" factor instead of the "strength" factor). Given this and as a starting place, in our first research question, we sought to investigate what the content of singular ILT dimensions are in our sample. Moreover, a first-year college student sample (versus a mixed-year sample of college students) may provide unique insights.

Research Question 1. What ILT dimensions do firstyear college students possess? Although there seems to be consistency over time in the traits individuals ascribe to leaders, these prior results suggest that the traditional factor-based approach to measuring ILTs is limited. Not only do factor-based operationalizations of ILTs not allow for deviations or changes in the predetermined list of ILT traits, but they also fail to allow for the examination of multi-trait ILT schemas. Thus, we suggest revisiting original conceptualizations of ILT complexity in defining and operationalizing beliefs about the traits and characteristics of effective leaders.

ILT Constellations. As noted by Lord and colleagues (1984), one's cognitive categorization of "leader" is hierarchical, possessing both vertical and horizontal dimensions. At the highest, superordinate level, are the most prototypical attributes one ascribes to all leaders. Moving down the hierarchy to the basic level, are more detailed and differentiated attributes; this is where individuals distinguish between different contexts and types of leaders (e.g., military leaders versus business leaders). Finally, the most nuanced level is the subordinate level. At this level, are the most prototypical attributes related to specific types of leaders (e.g., church leaders). Moving down the hierarchy, attributes of a leader become less inclusive and more distinctive. Fundamental to this hierarchy of leadership categories is the assumption that one's theory of leadership contains multiple attributes, behaviors, and traits.

Although researchers have long acknowledged that ILTs are multi-dimensional constructs comprised of multiple factors, they continue to use a factor-based (i.e., fixed attribute set) approach in ILT research. A factor-based approach oversimplifies the complexity of ILTs by focusing on each leader characteristic in isolation (e.g., charismatic). This approach to measuring ILTs fails to consider that ILTs vary not only in content but also in complexity. Therefore, the factor-based, fixed attribute set approach to understanding ILTs is a limitation of prior research (Junker \& van Dick, 2014). We aim to address this limitation in the present study by using a more nuanced and multi-faceted approach to studying ILTs, namely one that emphasizes ILT complexity and structure, which we conceptualize as ILT constellations.

ILT constellations refer to the cognitive schema one holds regarding the profile of traits and characteristics of effective leaders. The basic idea here is that an individual's mental model of an effective leader cannot be boiled down to a list of singular characteristics. Instead, we perceive an effective leader as consisting of multiple characteristics which differ in degree in 
relation to other characteristics. In contrast, a simplistic ILT consists of a singular defining characteristic (e.g., strength). As ILTs increase in complexity, leaders are defined based on a constellation (i.e., an interrelated set or profile) of characteristics (e.g., strength, sensitivity, integrity, and charismatic). An individual with a complex understanding of leadership would identify multiple characteristics defining a leader. For example, simultaneously holding an ILT that a leader is both "strong" and "sensitive" reflects a more nuanced and complex understanding of what it means to be a leader.

Some prior research has captured ILT complexity, but it is far less common than the typical factor-based approach. For instance, Foti and colleagues (2012) identified four ideal leader profiles that capture multiple ILT dimensions at once. They found that those with a "laissez-faire" leader profile tended to provide lower than average ratings on several ILT dimensions, whereas those with a "prototypical" leader profile tended to provide higher than average ratings on sensitivity, dedication, and intelligence and lower than average ratings on tyranny. Yet, Foti et al. used the traditional fixed scale list of traits (i.e., Epitropaki \& Martin, 2004) as their starting point and, thus, were limited in the possible ILT profiles that could emerge.

A fixed-scale, factor-based approach does not capture this complexity; thus, our understanding of ILTs based on prior research is limited. Instead, examining a constellation of free-response ILTs may be more informative in understanding the tone and depth of an individual's mental schema defining the term "leader." The constellation approach aligns with the move toward complexity and trait profiles in leadership research, particularly in recognizing the multiplicity of leader attributes (Zaccaro, 2012). A constellation approach also recognizes the increased complexity of the leadership context and the need for leaders to match that complexity (i.e., the law of requisite complexity; Lord et al., 2011). Therefore, the first purpose of our study is to investigate the utility of conceptualizing ILTs as a constellation of effective leader attributes.
Research Question 2. What ILT constellations do first-year college students possess?

ILT Malleability. Whereas early ILT theorizers (Rush \& Russell, 1988) supported the idea that a person's ILTs can change over time, leadership categorization theory suggests that once ILTs are formed as cognitive schemas, they are difficult to change (Reger \& Palmer, 1996). In support of this assertion, the only longitudinal investigation assessing ILT malleability found nonsignificant changes in ILTs over one year in a traditional organizational setting using the factor-based model (Epitropaki \& Martin, 2004). However, the impact of trigger events, or developmental experiences, on leader outcomes such as skill development (DeRue \& Wellman, 2009), perceived leader effectiveness (Seibert et al., 2017), leader identity (Hammond et al., 2017), and leader development more generally (Gurvis et al., 2016; McCauley et al., 2010) is long-standing.

Moreover, extant research suggests that cognitive schemas, including ILTs, are malleable under certain conditions. Day and colleagues (2009) argued that understanding the role of timing of leader developmental experiences is critical. Major periods of transition - like one's first year in college - may open individuals up to benefit from developmental experiences (Reichard et al., 2013). Exposure to opposing ideas, new role models, diverse and novel experiences, and changes in context can change previously formed schemas (Brown \& Lord, 2001; Labianca et al., 2000; Poole et al., 1989). Such developmental experiences challenge individuals to try new skills not previously associated with leadership and provide the opportunity to receive feedback, which may prompt a re-evaluation of assumptions and beliefs about leaders. As we know from research on leader development, challenge is one of the three chief components of development, along with feedback and support (Van Velsor et al., 2010).

In our final research questions, we seek to understand whether the singular dimensions and constellations of ILTs reported among students entering college differ from those reported at the end of their first 
year. The first year of college, a transitional period in young adults' lives marked by exposure to new ideas, experiences, and people, can be a critical period where they gain a new understanding of leadership. So, the way students view leaders may change over the first year. New experiences that challenge an individual's implicit theories require the adaption of their cognitive schemas to fit the new information (Poole et al., 1989). As a result, ILTs likely become more complex and multifaceted throughout experience, particularly novel experience.

Research Question 3. To what extent do the dimensions of ILTS change throughout a significant developmental experience?

Research Question 4. To what extent do ILT constellations change throughout a significant developmental experience?

\section{Methods}

Participants. Participants were first-year college students from a large Midwestern land-grant state university. We identified eligible participants as entering students who received a university "leadership scholarship" or had enrolled in an introductory leadership course in their first semester of college. We used a cohort design from 2011-2015, inviting the participation of approximately 1,000 first-year students each year. Across all cohorts, 276 students responded to both Time 1 (start of Freshman year) and Time 2 (end of Freshman year) surveys. Roughly 60 students participated in each cohort, except for in 2011 which only yielded 37 participants. Most participants were female (65\%) and Caucasian (86\%) with an average age of $18(S D=0.78)$. Self-report ACT scores ranged from 18 (40th percentile) to 35 (99th percentile), with a sample mean of $27.60(S D=4.01)$.

Measures. As part of a larger longitudinal study, we collected data at two points in time - at the beginning of the first year in college (Time 1) and at the end of the first year in college (Time 2).

Implicit leadership theories coding. ILTS were assessed by asking participants to list between one and ten traits or behaviors of effective leaders. Four Psychology graduate students and an assistant professor of leadership studies contentcoded the 4,330 ILT traits reported by participants. Using open coding (Corbin \& Strauss, 2008), we generated an initial set of 15 ILT themes that was reduced to nine final themes to eliminate overlap. When applicable and to enable comparison, we used similar language as prior research by Offermann and colleagues (1994) and Epitropaki and Martin (2004) to describe the ILT themes. Two coders independently sorted each participant's responses into the most representative theme. Coders resolved discrepancies through discussion. The average interrater reliability was high (Cohen's kappa $=.82$ ).

The nine themes identified included sensitivity, integrity, charisma, dedication, intelligence, strength, communication, organization, and openness (see Table 1). The tenth category of "other" was also included containing traits or behaviors that did not fit well into one of the nine categories and did not emerge as a distinct tenth theme. As opposed to removing the traits that did not fit in with the nine categories, we felt it was essential to retain them in the "other" category to be both exhaustive and inclusive. 


\section{Table 1}

Descriptions of ILT Qualitative Coding Categories

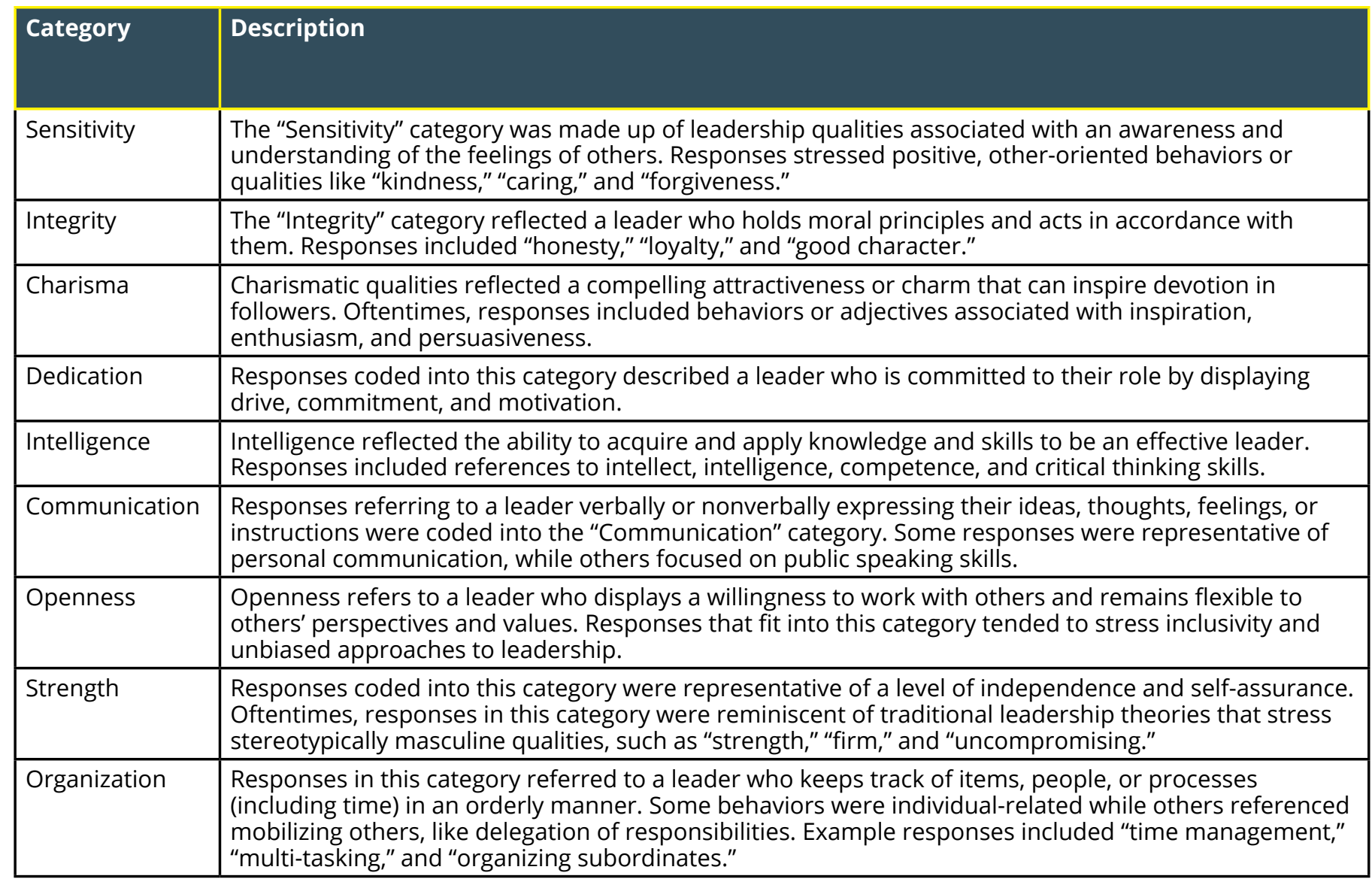

Note. Qualitative responses were coded into one of the 9 categories above based on an iterative process followed by four independent coders.

\section{Analyses and Results}

In this section, we describe our analysis approach and results to address our research questions and exploratory analysis.

ILT Content. Our first two research questions related to the content of ILT (1) dimensions and (2) constellations. Beginning with the traditional factorbased approach, we found that several of the singular ILT themes we identified in our study were similar to those identified in previous research (Offermann et al., 1994) including the following: sensitivity, charisma, dedication, intelligence, and strength. Unlike past research, the negative prototype dimensions (i.e., masculine, tyrannical), as well as the positive prototype dimension of attractive, were not identified in the data. This finding is likely an artifact of our ILT measurement method where we asked participants to state the traits and characteristics of an "effective leader" rather than "leader." Additional prototype dimensions that emerged in our sample were integrity, communication, openness, and organization. Of these, integrity was the second most reported ILT dimension at both Time 1 and Time 2. Going beyond the factor-based approach, the contribution of this study, however, is to examine ILT constellations rather than ILTs in isolation.

ILT Constellations. Thus, to address our second research question regarding ILT constellations content, we conducted an agglomerative hierarchical cluster analysis by grouping participants' coded responses to the ILT items at Time 1 and at Time 2 . 
Agglomerative hierarchical clustering is an iterative, bottom-up technique of clustering where each case begins as its own cluster. At each step of the analysis, cases are combined into clusters to minimize withincluster variance and maximize between-cluster variance by calculating the distance between each case or cluster (Rokach \& Maimon, 2005). We calculated the difference between each pair using squared Euclidean distance. Next, coded responses were grouped using Ward's (1963) linkage method to minimize withingroup differences. We used the elbow method (Ketchen \& Shook, 1996) to determine the number of clusters by examining a scree plot, which indicated that four clusters best explain coded ILT responses at each Time 1 and Time 2.

The composition of dominant themes for each of the four constellations was consistent at Time 1 and Time 2 (see Table 2). Therefore, the make-up of the ILT themes for each matched constellation was equivalent at Time 1 and Time 2 for constellation $A(\chi 2(9)=0.69, p=.99)$, constellation $B(\chi 2(9)=1.10, p=.99)$, constellation $C$ $(\chi 2(9)=3.83, p=.92)$, and constellation $D(\chi 2(9)=1.38$, $\mathrm{p}=.99)$. The ILT constellations are described in Table 2 and visually depicted in Figure 1.

\section{Table 2}

Descriptions of ILT Constellations

\begin{tabular}{|l|l|}
\hline Constellation & \multicolumn{1}{l|}{ Description } \\
\hline A & Constellation A was characterized by lower levels of all ILT themes. Time 1: N = 154; Time 2: N = 47. \\
\hline C & $\begin{array}{l}\text { Constellation B was distinguished by a preference for adjectives and behaviors related to a strong } \\
\text { sense of integrity at both time points. At Time 2, integrity decreased slightly (but was still the dominant } \\
\text { theme) and charismatic and dedication slightly increased. Time 1: N = 26; Time 2: N = 63. }\end{array}$ \\
\hline D & $\begin{array}{l}\text { Respondents placed into Constellation C identified effective leaders as those who readily display } \\
\text { sensitivity at both time points. A secondary, but also dominant theme was integrity at both time } \\
\text { points. At Time 2, sensitivity and integrity slightly decreased (but were still the dominant themes) and } \\
\text { charismatic slightly increased. Time 1: N = 47; Time 2: N = 91. }\end{array}$ \\
\hline $\begin{array}{l}\text { Constellation D included respondents who described demonstrates dedication as the dominant theme } \\
\text { at both time points, though it showed a slight decrease at Time 2. Sensitivity was a secondary, but also } \\
\text { dominant, theme at both time points, slightly decreasing at Time 2. Integrity was a dominant secondary } \\
\text { theme at Time } 1 \text { but decreased at Time 2. Whereas, Charismatic and Openness increased from Time 1 } \\
\text { to be secondary themes at Time 2. Time 1: N = 49; Time 2: N = 75. }\end{array}$ \\
\hline
\end{tabular}

Note. Based on results of a hierarchical cluster analysis, respondents were placed into one of four constellations.

\section{Figure 1}

Visualization of Four Constellations at Time 1 and Time 2

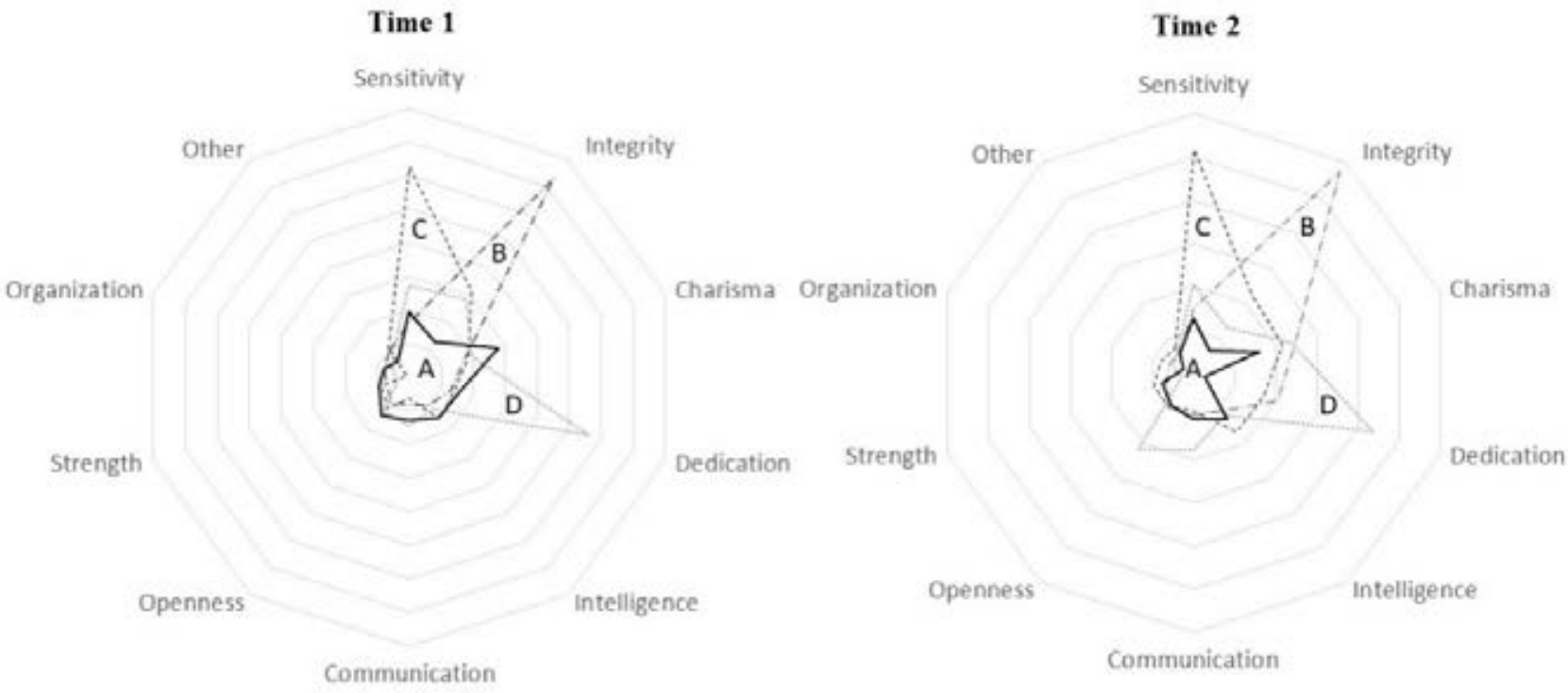


Low levels of several ILT themes characterized constellation $A$ and, thus, it lacked any emergent dominant ILT theme. The make-up of constellations $B, C$, and D, however, was dominated by one or more ILT themes. Specifically, constellation B was distinctive in that integrity was the most frequently reported ILT theme. Constellation $\mathrm{C}$ was dominated by sensitivity, with a secondary ILT theme of integrity. Finally, dedication was the hallmark ILT theme in constellation D, supported by charisma and openness.

ILT Malleability. Next, we address research question 3, which asked the degree to which ILT dimensions change throughout a significant developmental experience. To describe the relative dominance of ILT themes across Time 1 and Time 2, we calculated the mean frequencies of each ILT category. As shown in Figure 2, the most dominant ILT themes at both time points were sensitivity, followed by integrity. Charisma and dedication were also dominant themes at both time points. At first glance, based on the factor-based approach, and aligned with prior research (Offermann \& Coats, 2018), it appears that ILTs remain stable over time. However, by using cluster analysis, we take a deeper look at if and how ILT constellations membership change over time in our final research question.

\section{Figure 2}

Mean Frequencies for Qualitative Coding Categories Comparing Time 1 and Time 2

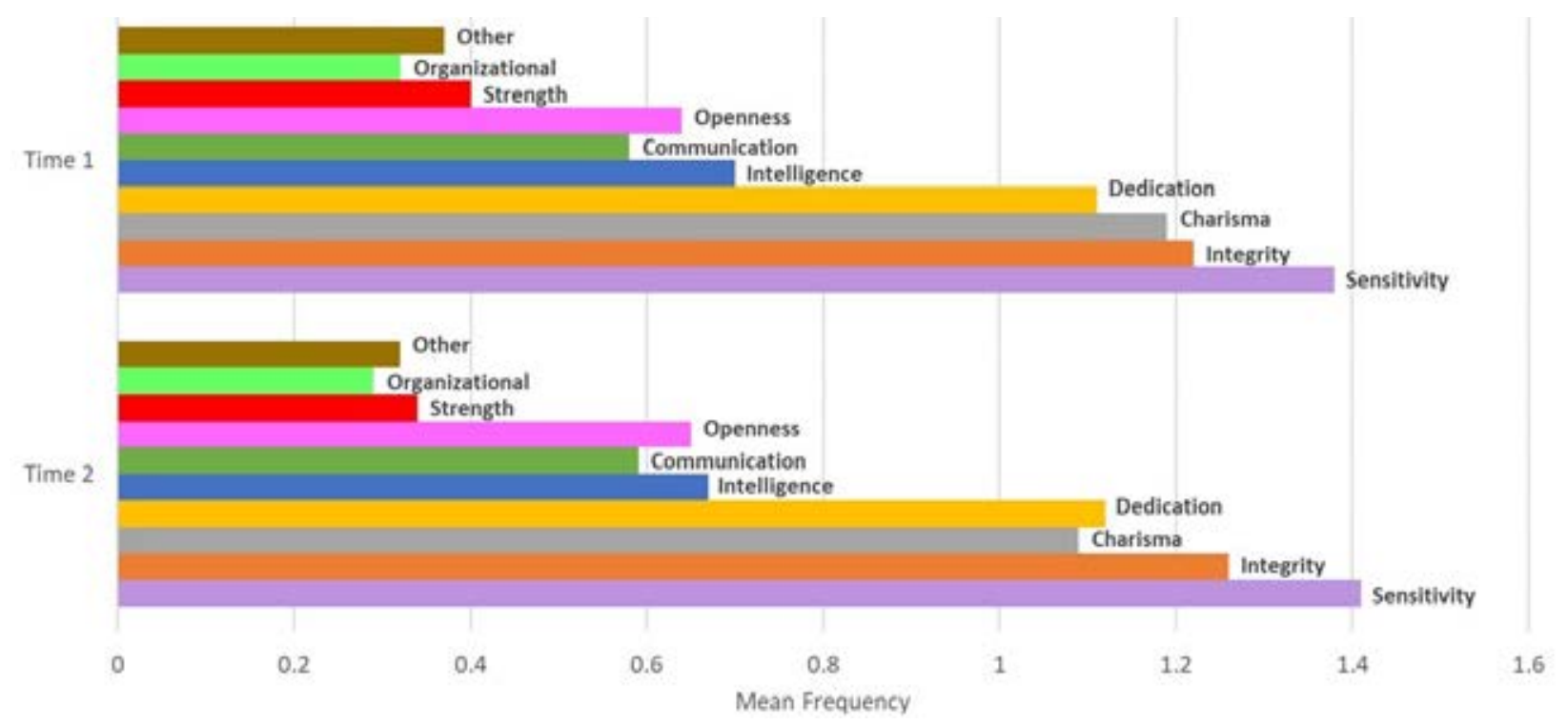

To address research question 4, which asked the extent to which ILT constellations change over time, we examine changes in membership in each constellation cluster from Time 1 to Time 2 . As shown in Figure 3, constellation A (i.e., non-descript ILT) was the most frequently reported constellation at Time 1 , classifying $55.80 \%$ of entering students $(n=154)$, and the least frequent at Time 2, classifying only $17.03 \%$ of students finishing their first year of college. Constellation A (non-descript ILT) was the only cluster to show a decrease in membership from Time 1 to Time 2. Results of a chi-square test indicated that these shifts in group membership per constellation across time points were statistically significant ( $\chi 2(3)$ $=295.61, \mathrm{p}<.001)$ with more students in constellation A (i.e., non-descript ILT) at the start of the first year of college and more students in constellations B (i.e., integrity dominated ILT), C (i.e., sensitivity and integrity dominated ILT), and D (i.e., dedication and sensitivity dominated ILT) at the end of the first year of college. When viewed through the constellation perspective, these findings indicate that ILTs do, in fact, change throughout a developmental experience. 


\section{Figure 3}

Frequencies of Students by Constellation at Time 1 and Time 2

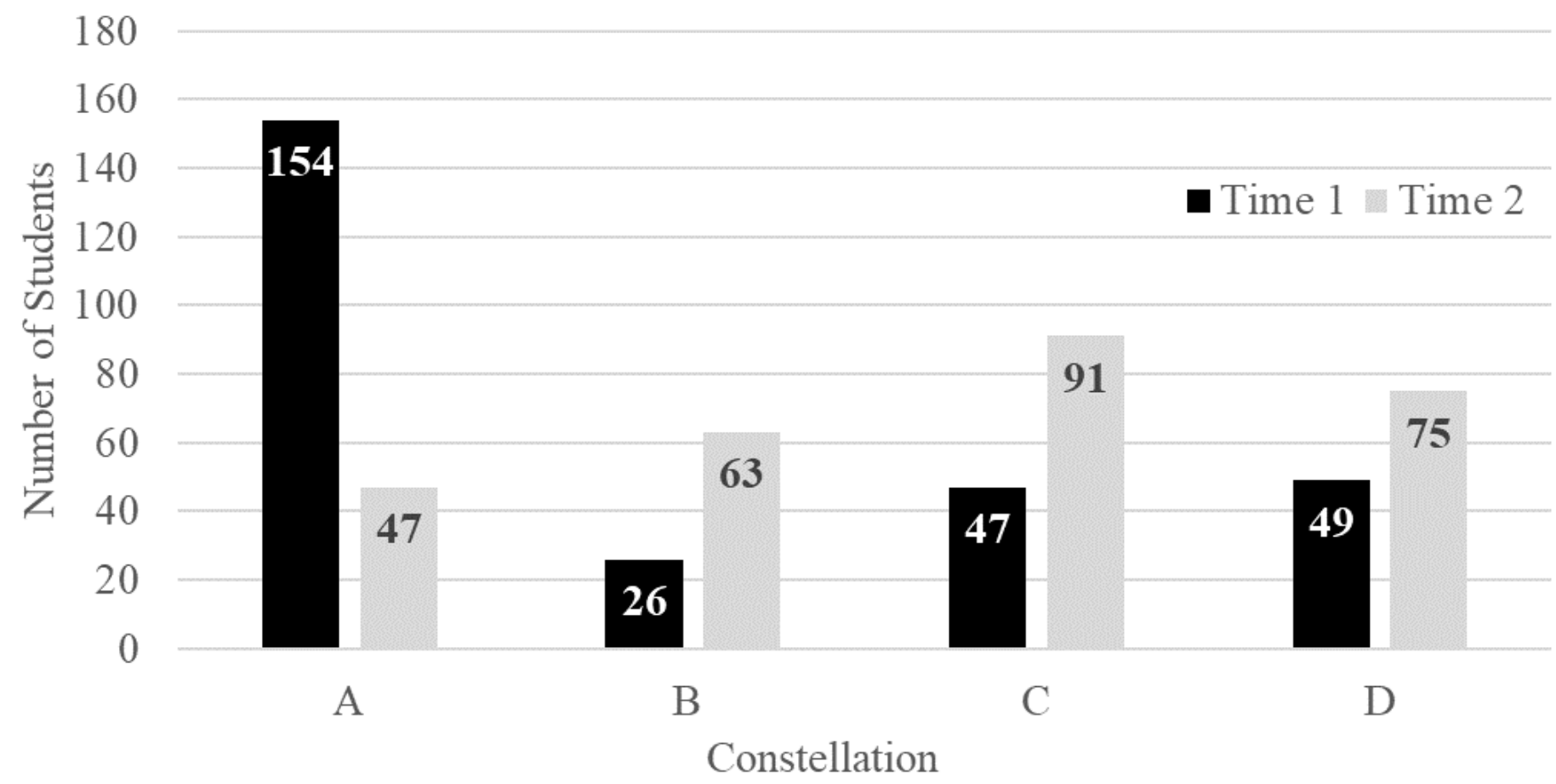

Note. $\chi 2(3)=295.6, p<.0001$.

Exploratory Analysis. In an exploratory analysis, we sought to examine whether differences in membership of constellation A (non-descript ILT) at Time 1 and Time 2 depended on the completion of leadership coursework (see Table 3). Whereas only three of the 27 students $(11 \%)$ who completed leadership coursework remained in constellation A at Time 2, 35 out of 127 students (28\%) who did not complete leadership coursework remained in constellation $A$ at Time 2. Among students who began their college education in constellation $A$, those who completed leadership coursework were two and a half times more likely to change their ILT constellation than those who did not take a course on leadership. A significant McNemar test revealed differences in constellation A membership at Time 1 and Time 2 was related to the completion of leadership coursework (OR $=2.54$, $p<$ .001). In answering research questions 2 and 4, we see four ILT constellations emerge, and although the makeup of the four constellations remains consistent over time, the frequency of membership does change. At least a portion of the movement away from constellation A (non-descript ILT) can be attributed to the completion of leadership coursework. However, moving out of constellation A may also be associated with many other developmental experiences during one's freshman year of college that were not captured in this study.

\section{Table 3}

Frequencies of Membership in Constellation $A$ by Completion of Leadership Coursework

\begin{tabular}{|c|c|c|}
\hline & $\begin{array}{c}\text { Leadership } \\
\text { Coursework }\end{array}$ & $\begin{array}{c}\text { Non-leadership } \\
\text { Coursework }\end{array}$ \\
\hline $\begin{array}{c}\text { Constellation A at } \\
\text { Time 1 }\end{array}$ & 24 & 92 \\
\hline $\begin{array}{c}\text { Constellation A at } \\
\text { Time 1 and 2 }\end{array}$ & 3 & 35 \\
\hline
\end{tabular}

Note. Table includes participants who were members of Constellation A at Time 1 ( $N=154)$. McNemar test revealed a significant change in Constellation A membership from Time 1 to Time 2 related to completion of leadership coursework. 


\section{Discussion}

The transition from high school to college provides exposure to new opportunities to engage in leadership roles and activities, such as joining on-campus clubs and volunteering in community outreach programs, and completion of leadership coursework. Such developmental experiences have the potential to promote a more complex and differentiated view of leadership (Komives et al., 2005), and what it means to be a leader (i.e., ILTS).

ILT Content. The first purpose of the current paper was to qualitatively examine the content of the ILTS of first-year college students. As such, this paper contributes to the leader development and college student development literature by providing a prospective, longitudinal, and descriptive examination of ILTs and extends our understanding of the content of ILTS.

Just as baby boomers and millennials have different music and fashion preferences, different generations and cultures are likely to have different leadership preferences based on significant cultural events occurring within their generation. Cross-generational comparisons provide an interesting perspective because of the socio-cultural nature of ILTs (Gerstner \& Day, 1994; Holmberg \& Akerblom, 2006). Given cultural shifts, previous ILTs may be less prevalent in today's youth (e.g., masculinity), whereas there may be new ILTs that have entered the cultural milieu (e.g., politicking). We did not initially set out to uncover whether ILT dimensions are the same today as they were in the 1990s and early 2000s because of the recent update by Offerman and Coats (2018). Instead, we asked participants about "effective" leader traits as opposed to leader traits, in general. Thus, readers must interpret any differences in our findings compared to previous generations/studies with this approach in mind. Despite this, we see slight differences compared to studies on prior generations. We found that five of the nine themes identified in the present study overlapped with Offermann et al.'s
(1994) ILT factors including sensitivity, intelligence, strength, dedication, and charisma.

Specifically, the most frequently reported ILT theme at both Times 1 and 2 was sensitivity, or an awareness of the feelings of other people. Examples include sympathy, compassion, understanding, sincerity, forgiving, helpful, respectful, courteous, considerate, caring, supporting, empathetic, kind, and friendly. This finding is interesting in light of the prior research findings that sensitivity is more strongly associated with feminine leadership, whereas masculinity, strength, and tyranny are more strongly associated with masculine leadership (Johnson et al., 2008).

Of these stereotypically masculine leadership ILT traits, only strength emerged in the current study. The absence of attractiveness and masculinity as themes in our sample may reflect a societal shift towards greater diversity in leadership representation.

The absence of tyranny, labeled anti-prototypical by Epitropaki and Martin (2004), perhaps reflects a changing contemporary view of leaders in a more positive light, or again merely an artifact of our method, sample, or the phrasing of the question regarding "effective" leader rather than simply "leader." At face value, preferences for feminine leader traits (e.g., sensitivity) implies a shift in favor of women leaders; and this finding aligns with meta-analytical results indicating that the masculine construal of leadership has decreased over time (Koenig et al., 2011). However, Johnson et al. (2008) found that gender stereotypes require women leaders to embody both sensitivity and strength to be perceived as effective, reflecting the importance of the contextually constrained nature of ILTs (Lord et al., 2001) and the utility of ILT constellations.

The changing social and leadership context is also illustrated in the addition of four new ILT themes found in the current study, which go beyond older research on ILT content, including integrity, communication, organization, and openness. By far, the most frequent of these new themes was integrity, defined as holding moral principles and acting by them. Traits listed include honest, trustworthy, ethical, loyal, humble, moral, honorable, transparent, role model, character, 
fair, servant, and selfless. Although Offerman and colleagues' (1994) and Offerman and Coats' (2018) study participants generated similar traits related to integrity and ethics, in both prior studies such traits were subsumed under the theme of sensitivity. Rather, we found that integrity emerged as one of the most dominant themes of ILT traits.

Perhaps this shift toward integrity in the current decade is a reaction from the fraud scandals at the beginning of the current century (e.g., Enron, Worldcom, Lehman Brothers, and Bernie Madoff; Kalshoven et al., 2011), an emphasis on the effects of destructive leadership (Schyns \& Schilling, 2013), or a shift toward character-based education in schools (Wright, 2015). A shift in defining what characterizes a leader has also been observed in the "dramatic increase in scholarly interest in the topic of authentic leadership" in recent years (Gardner et al., 2011, p. 1120). These findings imply that a new generation of adults expect leaders to embody ethics and integrity. When a leader demonstrates a high level of character, today's young adults are likely to evaluate that leader favorably.

Although several dimensions from the fixed attribute set often used in research (Offermann et al., 1994) emerged in our qualitative data, we identified different dimensions of effective leaders that would have been otherwise missed (i.e., integrity, communication, openness, and organization). Addressing concerns raised by Alipour et al. (2017) and others, regarding missing dimensions of ILTs in current research, content coding of qualitative data allows researchers to examine new emergent themes not previously considered. This is particularly important when conducting ILT research across generations and societies, as culture influences our perceptions of effective leadership (House, Javidan, Hanges, \& Dorfman, 2002).

Given that both our study and the study by Offerman and Coats (2018) found some slight deviation from prior research in the content of ILT themes that emerged through open-ended responses, we must reconsider the typical measurement approach used in ILT research. As noted, most ILT studies present respondents with a pre-determined list of traits and ask them to rate the extent to which each is characteristic of a leader. We conclude that this approach is limited in two ways.

First, it limits the range of possible traits a respondent can endorse as characteristic of leaders. Thus, providing a pre-determined, possibly outdated list of ILT characteristics misses important information. This is particularly notable given that the dominant conversants in the field of leader development are Caucasian males (Vogel, Reichard, Batistic, \& Cerne, in press), who mostly study Caucasian males. By opening the operationalization of ILT themes, not only are researchers avoiding the perpetuation of the dominant Caucasian, male expectations of leaders (Dugan, 2017); but they are also opening up the likelihood of the emergence of more nuanced ILTS held by members of various gender, racial, ethnic, and generational groups.

Second, the factor-based measurement approach focusing on singular traits in isolation is not reflective of the complexity of an individual's schema of what characterizes a leader, which we instead conceptualize as a constellation of ILT traits. Further, the factor-based approach, at least in our study, seems to mask observing changes in ILT over time. Specifically, although there appears to be consistency in the singular ILT traits reported over time, when we examine ILT constellations, we do observe changes in how individuals view effective leaders over the course of a developmental experience.

Malleability of ILT Constellations. Thus, the second purpose of the present study was to explore a new way of understanding ILTs, namely as a constellation of themes, and how ILT constellations change throughout a developmental experience. When using the traditional factor-based approach to examining ILTs, by having participants list the characteristics of a leader, we find very little change over the first year of college. Thus, this typical methodological approach masks changes in ILTs over time. However, when considering one's reported ILT characteristics 
together, as a constellation, we do see significant change over time.

Change in ILT constellation is particularly evident by the number of students who shifted dramatically at the end of the first year of college away from the nondescript, varied constellation A toward the other three constellations that had dominant themes present. This shift indicates that as students gain experience and knowledge over the first year of college, they develop a clearer perception of the specific characteristics of effective leaders. Rather than a hodge-podge of nothing in particular or lack of clear ILT, by the end of the first year of college, students more frequently report specific leader characteristics indicating a refinement in their mental models. Students come to see an effective leader in a clearer way indicating that education and developmental experiences have a significant impact on students' ILTS. Thus, a major contribution of the current study is revisiting the idea that individuals conceptualize a leader as a constellation of traits and that this conceptualization is open to change over time, particularly following leader development coursework.

Interestingly, only $8 \%$ (3 of 38 ) of students that remained in constellation $A$ (i.e., non-descript ILT) from Time 1 to Time 2 took a leadership class during their first year in college. Of the 116 students who left constellation $A$ from Time 1 to Time 2, 21\% $(n=$ 24) took a leadership class. This exploratory analysis indicates that taking a leadership class during the first year of college is positively related to movement out of the generic constellation A, characterized by low endorsements of ILT traits, to other constellations defined by a dominant ILT trait. However, we feel it is important to note that other unmeasured first-year experiences were likely drivers of this change in ILT constellation membership, given that $79 \%(n=92)$ of students who left constellation A did not take a leadership class. All that being said, the results of the current study indicate that (a) individuals do possess multi-faceted constellations of ILTs, (b) those ILT constellations change throughout one's first year in college, and (c) undergraduate leadership education is one factor that plays a role in the change in ILT constellations.

\section{Limitations and Future Research}

Two main limitations of this study include the sample and final coding scheme. Regarding the sample, a midwestern U.S. sample is limited in generalizability to other samples of college students across the U.S. and around the world. Midwestern values, rural ways of living, and the predominance of Caucasian participants provide some commonalities in student backgrounds that likely impact ILTs. A similar study of first-year college students in New York City or Los Angeles may yield different ILT themes and constellations. We expect, though, future research in more diverse samples will still find similar changes in ILT constellations, with more clearly defined ILT constellations accompanying more experience and education; and our demonstrated methodology allows for testing that. Second, our final coding scheme - although reliability rated - may be criticized for its division into specific themes. For example, one might argue that the inclusivity component of the "openness" theme could have been included as part of "integrity." Future researchers can address this by allowing themes to emerge from open-ended responses.

Future research utilizing an ILT constellations approach is needed. Because of the additional specificity, we expect ILT constellations to be stronger predictors of important leadership outcomes such as perceptions of leader effectiveness and likeability and leadermember exchange than a single ILT trait. A leader who matches the followers' ILT constellations will be perceived as more effective, likable, and have strong relationships with those followers. We also encourage future research to examine the relationship between ILT constellations and self-views. Individuals with more complex and differentiated ILT constellations are expected to have more positive views of oneself as a leader because of the higher probability of possessing more leader-like traits. By endorsing a leader identity in this way, individuals with ILT constellations higher in complexity would be more likely to seek out leadership 
roles and developmental opportunities.

Although the ILT constellation approach allows examination of the content, complexity, and structure of ILTs, the approach we utilize in this paper is challenging to quantify and, thus, challenging to study over time. Future research can quantify ILT complexity based on the number of unique characteristics one uses to define a leader. Specifically, future research can quantify ILT complexity by first asking participants to list one to ten the traits of effective leaders. ILT complexity can then be calculated based on the number of different themes in which a participant reported each trait category. Meaning, it is not simply the number of ILT traits reported, but the breadth of themes reported. For example, a low ILT complexity response is observed when a participant reports five leader traits that load onto the same theme (e.g., kind, caring, forgiving, respectful, courteous). Because all the traits reported define one ILT dimension (i.e., sensitivity), the ILT complexity score equals one. On the other hand, a higher complexity response is observed when a participant reports five leader traits that load onto different themes (e.g., kind, honest, inspirational, committed, competent). Because each trait reported defines a different ILT dimension (i.e., sensitivity, integrity, charisma, dedication, intelligence), the ILT complexity score equals five. Using this approach, future researchers can examine how ILT complexity changes over time and what important outcomes it may predict (e.g., leader identity and emergence).

Finally, we contribute one of the first longitudinal investigations of ILT malleability and find support for the malleability of ILT constellations following the first year of college. Future studies should assess the degree to which ILTs remain malleable as individuals gain life and leadership experience. Mental models may become increasingly difficult to change as our experiences reinforce existing schemas. More longitudinal studies are needed to investigate the impact of developmental experiences on ILTs at different life or career stages.

\section{Conclusion}

In summary, we extended prior research on ILTs by examining ILTs of a current generation of first-year college students. We found the addition of several ILT themes and the absence of anti-prototypical ILTS themes found in previous research. We theorized and empirically demonstrated that how students define a leader goes beyond a singular characteristic to be reflected by a constellation of traits and that following a year in college, students move from a generalized, non-specific ILT constellation to a more specific one. Future research is needed to examine further developmental factors predicting ILTs constellations and their outcomes. As students engage in leader education, they gain clarity in their understanding of ILTs. Undergraduate leadership education, particularly for first-year college students, is encouraged. 


\section{References}

Alipour, K. K., Mohammed, S., \& Martinez, P. N. (2017). Incorporating temporality into implicit leadership and followership theories: Exploring inconsistencies between time-based expectations and actual behaviors. The Leadership Quarterly, 28(2), 300-316. https://doi.org/10.1016/j.leaqua.2016.11.006

Brown, D. J., \& Lord, R. G. (2001). Leadership and perceiver cognition: Moving beyond first order constructs. In M. London (Ed.), How people evaluate others in organizations (pp. 181-202). Lawrence Erlbaum.

Carnes, A., Houghton, J. D., \& Ellison, C. N. (2015). What matters most in leader selection? The role of personality and implicit leadership theories. Leadership and Organization Development Journal, 36(4), 360-379. https://doi.org/10.1108/LODJ-06-2013-0087

Corbin, J. M. \& Strauss, A. (2008). Basics of qualitative research: Grounded theory procedures and techniques (3rd Ed.). Sage Publications.

Day, D. V., Harrison, M. M., \& Halpin, S. M. (2009). An integrative approach to leader development: Connecting adult development, identity and expertise. Taylor \& Francis Group.

DeRue, D. S., \& Wellman, N. (2009). Developing leaders via experience: The role of developmental challenge, learning orientation, and feedback availability. Journal of Applied Psychology, 94(4), 859-875. http://doi. org/10.1037/a0015317

Dugan, J. P. (2017). Leadership theory: Cultivating critical perspectives. Jossey-Bass.

Engle, E. M., \& Lord, R. G. (1997). Implicit theories, self-schemas, and leader-member exchange. Academy of Management Journal, 40(4), 988-1010.

Epitropaki, O., \& Martin, R. (2004). Implicit leadership theories in applied settings: Factor structure, generalizability, and stability over time. Journal of Applied Psychology, 89(2), 293-310.

Epitropaki, O., \& Martin, R. (2005). From ideal to real: A longitudinal study of the role of implicit leadership theories on leader-member exchanges and employee outcomes. Journal of Applied Psychology, 90(4), 659-676.

Epitropaki, O., Sy, T., Martin, R., Tram-Quon, S., \& Topakas, A. (2013). Implicit leadership and followership theories "in the wild": Taking stock of information-processing approaches to leadership and followership in organizational settings. The Leadership Quarterly, 24(6), 858-881. https://doi.org/10.1016/j. leaqua.2013.10.005

Fiske, S. T., \& Taylor, S. E. (1991). Social cognition (2nd ed). McGraw-Hill Book Company.

Foti, R. J., Bray, B. C., Thompson, N. J., \& Allgood, S. F. (2012). Know thy self, know thy leader: Contributions of a pattern-oriented approach to examining leader perceptions. The Leadership Quarterly, 23(4), 702-717. https://doi.org/10.1016/j.leaqua.2012.03.007

Gardner, W. L., Cogliser, C. C., Davis, K. M., \& Dickens, M. P. (2011). Authentic leadership: A review of the literature and research agenda. The Leadership Quarterly, 22(6), 1120-1145. https://doi.org/10.1016/j. leaqua.2011.09.007

Gerstner, C. H., \& Day, D. V. (1994). Cross-cultural comparison of leadership prototypes. The Leadership Quarterly, 5(2), 121-134. https://doi.org/10.1016/1048-9843(94)90024-8 
Guillén, L., Mayo, M., \& Korotov, K. (2015). Is leadership a part of me? A leader identity approach to understanding the motivation to lead. The Leadership Quarterly, 26(5), 802-820. http://dx.doi.org/10.1016/j. leaqua.2015.05.001

Gurvis, J., McCauley, C., \& Swofford, M. (2016). Putting experience at the center of talent management [White Paper]. Center for Creative Leadership.

Hall, R. J., \& Lord, R. G. (1995). Multi-level information-processing explanations of followers' leadership perceptions. The Leadership Quarterly, 6(3), 265-287. https://doi.org/10.1016/1048-9843(95)90010-1

Hall, R. J., Workman, J. W., \& Marchioro, C. A. (1998). Sex, task, and behavioral flexibility effects on leadership perceptions. Organizational Behavior and Human Decision Processes, 74(1), 1-32. https://doi.org/10.1006/ obhd.1998.2754

Hammond, M., Clapp-Smith, R., \& Palanski, M. (2017). Beyond (just) the workplace: A theory of leader development across multiple domains. Academy of Management Review, 42(3), 481-498. https://doi.org/10.5465/ amr.2014.0431

Holmberg, I., \& Åkerblom, S. (2006). Modelling leadership_Implicit leadership theories in Sweden. Scandinavian Journal of Management, 22(4), 307-329. https://doi.org/10.1016/j.scaman.2006.10.002

House, R., Javidan, M., Hanges, P., \& Dorfman, P. (2002). Understanding cultures and implicit leadership theories across the globe: An introduction to project globe. Journal of World Business, 37(1), 3-10. https://doi. org/10.1016/S1090-9516(01)00069-4

Jelinek, M., Smircich, L., \& Hirsch, P. (1983). Introduction: A code of many colors. Administrative Science Quarterly, 28(3), 331-338.

Johnson, S. K., Murphy, S. E., Zewdie, S., \& Reichard, R. J. (2008). The strong, sensitive type: Effects of gender stereotypes and leadership prototypes on the evaluation of male and female leaders. Organizational Behavior and Human Decision Processes, 106(1), 39-60. https://doi.org/10.1016/j.obhdp.2007.12.002

Junker, N. M., \& van Dick, R. (2014). Implicit theories in organizational settings: A systematic review and research agenda of implicit leadership and followership theories. The Leadership Quarterly, 25(6), 11541173. https://doi.org/10.1016/j.leaqua.2014.09.002

Kalshoven, K., Den Hartog, D. N., \& De Hoogh, A. H. B. (2011). Ethical leadership at work questionnaire (ELW): Development and validation of a multidimensional measure. The Leadership Quarterly, 22(1), 51-69. https://doi.org/10.1016/j.leaqua.2010.12.007

Kenney, R. A., Schwartz-Kenney, B. M., \& Blascovich, J. (1996). Implicit leadership theories: Defining leaders described as worthy of influence. Personality and Social Psychology Bulletin, 22(11), 1128-1143. https://doi. org/10.1177/01461672962211004

Ketchen, D. J., \& Shook, C. L. (1996). The application of cluster analysis in strategic management research: An analysis and critique. Strategic Management Journal, 17(6), 441-458.

Koenig, A. M., Eagly, A. H., Mitchell, A. A., \& Ristikari, T. (2011). Are leader stereotypes masculine? a meta-analysis of three research paradigms. Psychological Bulletin, 137(4), 616-42. https://doi.org/10.1037/a0023557

Komives, S. R., Owen, J. E., Longerbeam, S. D., Mainella, F. C., \& Osteen, L. (2005). Developing a leadership identity: A grounded theory. Journal of College Student Development, 46(6), 593-611. https://doi.org/10.1353/ csd.2005.0061 
Labianca, G., Gray, B., \& Brass, D. J. (2000). A grounded model of organizational schema change during empowerment. Organization Science, 11(2), 235-257. https://doi.org/10.1287/orsc.11.2.235.12512

Lord, R. G., Brown, D. J., Harvey, J. L., \& Hall, R. J. (2001). Contextual constraints on prototype generation and their multilevel consequences for leadership perceptions. The Leadership Quarterly, 12(3), 311-338. https://doi.org/10.1016/S1048-9843(01)00081-9

Lord, R. G., Epitropaki, O., Foti, R. J., \& Hansbrough, T. K. (2020). Implicit leadership theories, implicit followership theories, and dynamic processing of leadership information. Annual Review of Organizational Psychology and Organizational Behavior, 7(1), 49-74. https://doi.org/10.1146/annurev-orgpsych-012119-045434

Lord, R. G., Foti, R. J., \& De Vader, C. L. (1984). A test of leadership categorization theory: Internal structure, information processing, and leadership perceptions. Organizational Behavior and Human Performance, 34(3), 343-378. https://doi.org/10.1016/0030-5073(84)90043-6

Lord, R. G., Foti, R. J., \& Phillips, J. S. (1982). A theory of leadership categorization. In J. G. Hunt, U. Sekaran, \& C. Schriesheim (Eds.), Leadership: Beyond establishment views. Southern Illinois University Press.

Lord, R. G., Hannah, S. T., \& Jennings, P. L. (2011). A framework for understanding leadership and individual requisite complexity. Organizational Psychology Review, 1(2), 104-127. https://doi. org/10.1177/2041386610384757

McCauley, C. D., Van Velsor, E., \& Ruderman, M. N. (2010). Introduction: Our view of leadership development. In E. Van Velsor, C. D. McCauley, \& M. N. Ruderman (Eds.) The Center for Creative Leadership handbook of leadership development (pp. 1-26). John Wiley \& Sons.

Nye, J. L. \& Forsyth, D. R. (1991). The effects of prototype-based biases on leadership appraisals: A test of leadership categorization theory. Small Group Research, 22(3), 360-379. https://doi. org/10.1177/1046496491223005

Offermann, L. R., \& Coats, M. R. (2018). Implicit theories of leadership: Stability and change over two decades. The Leadership Quarterly, 29(4), 513-522. https://doi.org/10.1016/j.leaqua.2017.12.003

Offermann, L. R., Kennedy, J. K., \& Wirtz, P. W. (1994). Implicit leadership theories: Content, structure, and generalizability. The Leadership Quarterly, 5(1), 43-58. https://doi.org/10.1016/1048-9843(94)90005-1

Poole, P. P., Gioia, D. A., \& Gray, B. (1989). Influence modes, schema change, and organization transformation. The Journal of Applied Behavioral Science, 25(3), 271-289.

Priest, K. L. \& Middleton, E. (2015). Exploring leader identity and development. In R. J.

Reichard, \& S. E. Thompson (Eds.) Leader Developmental Readiness: Pursuit of Leadership Excellence. New Directions for Student Leadership: Jossey-Bass (pp. 37-48).

Reger, R. K., \& Palmer, T. B. (1996). Managerial categorization of competitors: Using old maps to navigate new environments. Organization Science, 7(1), 22-39. https://doi.org/10.1287/orsc.7.1.22

Reichard, R. J., Tan, S. J., Wefald, A., \& Tolar, M. (2013, August 9 - 13). Timing of leader development support and developmental trajectories [Paper presentation]. Academy of Management 73 Annual meeting, Buena Vista, FL, United States.

Rokach, L., \& Maimon, O. (2005). Clustering methods. In O. Maimon \& L. Rokach (Eds.), Data mining and knowledge discovery handbook (pp. 321-352). Springer. 
Rosch, E. (1978). Principles of categorization. In E. Rosch \& B. Lloyd (Eds.), Cognition and categorization (pp. 2748). Lawrence Erlbaum.

Rush, M. C., \& Russell, J. E. A. (1988). Leader prototypes and prototype-contingent consensus in leader behavior descriptions. Journal of Experimental Social Psychology, 24(1), 88-104. https://doi.org/10.1016/00221031(88)90045-5

Schyns, B. \& Meindl, J. R. (2005). An overview of implicit leadership theories and their application in organization practice. In B. Schyns \& J. R. Meindl (Eds.), Implicit leadership theories: Essays and explorations (pp. 15-36). Information Age Publishing.

Schyns, B., \& Schilling, J. (2013). How bad are the effects of bad leaders? A meta-analysis of destructive leadership and its outcomes. The Leadership Quarterly, 24(1), 138-158. https://doi.org/10.1016/j.leaqua.2012.09.001

Seibert, S. E., Sargent, L. D., Kraimer, M. L., \& Kiazad, K. (2017). Linking developmental experiences to leader effectiveness and promotability: The mediating role of leadership self-efficacy and mentor network. Personnel Psychology, 70(2), 357-397. http://doi.org/10.1111/peps.12145

Sy, T., Shore, L. M., Strauss, J., Shore, T. H., Tram, S., Whiteley, P., \& Ikeda-Muromachi, K. (2010). Leadership perceptions as a function of race-occupation fit: The case of Asian Americans. Journal of Applied Psychology, 95(5), 902-19. https://doi.org/10.1037/a0019501

Van Quaquebeke, N. \& Van Knippenberg, D. (2012). Second-generation leader categorization research: How subordinates' self- and typical leader perceptions moderate leader categorization effects. Journal of Applied Social Psychology, 42(6), 1293-1319. https://doi.org/10.1111/j.1559-1816.2012.00899.x

Van Velsor, E., McCauley, C. D., \& Ruderman, M. N. (Eds.). (2010). The center for creative leadership handbook of leadership development. John Wiley \& Sons.

Walker, D. O. H., Reichard, R. J., Riggio, R. E., \& Hansbrough, T. K. (2020). Who might support a tyrant? An exploration of links between adolescent family conflict and endorsement of tyrannical implicit leadership theories. Journal of Leadership and Organizational Studies, 27(4), 340-356. https://doi. org/10.1177/1548051820931243

Ward, J. H. (1963). Hierarchical grouping to optimize an objective function. Journal of the American Statistical Association, 58(301), 236-244.

Wright, T. A. (2015). Distinguished scholar invited essay: Reflections on the role of character in business education and student leadership development. Journal of Leadership and Organizational Studies, 22(3), 253-264. https://doi.org/10.1177/1548051815578950

Zaccaro, S. J. (2012). Individual differences and leadership: Contributions to a third tipping point. The Leadership Quarterly, 23(4), 718-728. https://doi.org/10.1016/j.leaqua.2012.05.001 